Bangladesh J. Pl. Breed. Genet., 24(2): 19-24, 2011

\title{
GENETIC VARIABILITY FOR GRAIN QUALITY TRAITS IN AROMATIC RICE (Oryza sativa L)
}

\author{
Kaniz Fatema, M. G. Rasul, M. A. K. Mian and M. M. Rahman ${ }^{1}$ \\ Department of Genetics and Plant Breeding \\ Bangabandhu Sheikh Mujibur Rahman Agricultural University \\ Gazipur 1706, Bangladesh
}

\begin{abstract}
Forty five aromatic rice genotypes were evaluated to assess the genetic variability and diversity on the basis of nine characters. Significant variations were observed among the genotypes for all the characters (grain breadth $(\mathrm{mm})$, grain length $(\mathrm{mm})$, grain $\mathrm{L} / \mathrm{B}$ ratio, gelatinization temperature (score), gel consistency $(\mathrm{mm})$, amylose content $(\%)$, protein content $(\%), 1000$ grain weight (g) and grain yield per plant $(\mathrm{g})$ ) studied. High GCV, PCV, heritability and GA as observed in amylose content, grain length average and L/B ratio suggested that these three characters could be transmitted to the progeny. Multivariate analysis revealed that 45 genotypes were grouped into six clusters. There were marked variations in intra-cluster distances, which ranged from 0.482 to 7.851 . The highest intra cluster mean for five traits (amylose content, width average, L/B ratio, length average, 1000 grain weight) was obtained from cluster I constituted 10 genotypes. Thousand grain weight and amylose content have been found to contribute maximum towards genetic diversity in 45 genotypes of aromatic rice.
\end{abstract}

Key words: Rice (Oryza sativa $\mathrm{L}$ ), GCV, PCV, $\mathrm{D}^{2}$-statistic, grain yield

\section{INTRODUCTION}

Rice is the unique grain that is used as human food, unlike other cereals, which are also used extensively as feed (Swaminathan, 1999). Aromatic rice constitutes a small and special group of rice that is regarded as the best in quality and usually used for special dish preparation. Quality of rice may be considered from the view point of size, shape and appearance of grain, milling quality and cooking properties (Dela Cruz and Khush, 2000). The breeders seek rice grain with higher content of protein, vitamins and minerals. Bangladesh has a stock of above 7,000 rice germplasms of which around 100 are aromatic varieties (BRRI, 1997; Hamid et al., 1982). Most of our varieties are small and medium grained, unlike long grained rices in the world market. It is true that some small and medium-grained aromatic rice possess excellent aroma and other quality traits like elongation after cooking, taste etc. These could be excellent sources for improving quality in high yielding varieties. The improvement of aromatic rice requires its collection and evaluation of existing cultivars of Bangladesh. Genetic study of local germplasm of aromatic rice is the pre-requisite for the development of high yielding aromatic varieties. In crop improvement program, genetic variability for agronomic traits as well as quality traits in almost all the crops is important, since this component is

\footnotetext{
${ }^{1}$ Department of Horticulture, Bangabandhu Sheikh Mujibur Rahman Agricultural University, Gazipur 1706, Bangladesh.
} 
transmitted to the next generation (Singh et. al., 1996). Study of genetic divergence among the plant materials is a vital tool to the plant breeders for an efficient choice of parents for plant improvement. Genetically diverse parents are likely to contribute desirable segregants and/or to produce high heterotic crosses. Parents identified on the basis of divergence analysis for any breeding program would be more promising (Arunachalam, 1981). Grouping or classification of genotypes based on suitable scale is quite imperative to understand the usable variability existing among them. Different studies have been undertaken to study the variability and to characterize the aromatic rice varieties in different rice-growing countries but very few reports or research has yet been conducted to characterize or classify Bangladeshi aromatic rice. In view of the aforesaid discussion, a study was undertaken to determine physico-chemical and cooking qualities of grains and to estimate genetic relationship among the genotypes.

\section{MATERIALS AND METHODS}

The experimental material for the study was comprised of 45 aromatic rice genotypes which received from Bangladesh Rice Research Institute (BRRI). The experiment was conducted in a randomized complete block design with three replications at the experimental field of Bangabandhu Sheikh Mujibur Rahman Agricultural University (BSMRAU) during April to September, 2010. Data were recorded on grain length $(\mathrm{mm})$, grain breadth $(\mathrm{mm}), \mathrm{L} / \mathrm{B}$ ratio, 1000 grain weight $(\mathrm{g})$, yield per plant $(\mathrm{g})$, gelatinization temperature (score), gel consistency $(\mathrm{mm})$, amylose content $(\%)$ and protein content $(\%)$.

Genotypic and phenotypic variances were determined using the formulae of Johnson et al. (1955). Heritability and genetic advance were also estimated according to the method of Johnson et al. (1955). In order to assess the genetic diversity, $\mathrm{D}^{2}$-statistic has been adopted based on multivariate analysis developed by Mahalanobis (1936).

Table 1. List of different genotypes used in the experiment

\begin{tabular}{c|l|l|l|l|l}
\hline $\begin{array}{c}\text { Sl. } \\
\text { No. }\end{array}$ & $\begin{array}{c}\text { BRRI } \\
\text { Accession No. }\end{array}$ & $\begin{array}{l}\text { Name of the } \\
\text { genotypes }\end{array}$ & $\begin{array}{c}\text { Sl. } \\
\text { No. }\end{array}$ & $\begin{array}{c}\text { BRRI } \\
\text { Accession No. }\end{array}$ & Name of the genotypes \\
\hline 1. & 388 & Chinisakkor-1 & 24. & 4840 & Dubshail \\
2. & 397 & Chiniatob & 25. & 4343 & BR-5 \\
3. & 2027 & Kaminisaru & 26. & 7094 & BR-37 \\
4. & 2037 & Doirgura & 27. & 4341 & Khashkani \\
5. & 2041 & Premful & 28. & 4850 & Guamori \\
6. & 2402 & Rajbhog-1 & 29. & 4361 & Basmoti \\
7. & 2412 & Chinigura & 30. & 4761 & Sakkorkhora \\
8. & 2454 & Jessobalam & 31. & 983 & Dakshahi \\
9. & 2483 & Badshabhog-1 & 32. & 4831 & Jirabhog Finer \\
10. & 2384 & Badshabhog-2 & 33. & 2009 & Agali \\
11. & 2488 & Badshabhog-3 & 34. & 4355 & Badshabhog (colored) \\
12. & 2492 & Kalijira-1 & 35. & 352 & Kalgochi \\
13. & 2495 & Kalijira-2 & 36. & 387 & Chinisakkor-2 \\
14. & 2496 & Kalijira-3 & 37. & 865 & Rajbhog-2 \\
15. & 2502 & Radhunipagal-1 & 38. & 990 & Chinikamini-2 \\
16. & 2503 & Radhunipagal-2 & 39. & 2015 & Sarukamini \\
17. & 2528 & Hatisail & 40. & 2022 & Duksail \\
18. & 2939 & Awened-1 & 41. & 2481 & Badshabhog-4-Tapl-52 \\
19. & 2947 & Black & 42. & 2487 & Badshabhog-7-Tapl-59 \\
20. & 4737 & Uknimadhu & 43. & 2489 & Badshabhog-8-Tapl-61 \\
21. & 4754 & Bashmoti-1 & 44. & 2490 & Badshabhog-9-Tapl-62 \\
22. & 4815 & Kalijira Finer & 45. & 2491 & Badshabhog-9-Tapl-63 \\
23. & 4818 & Tilkapur & & & \\
\hline
\end{tabular}




\section{RESULTS AND DISCUSSION}

\section{Univariate analysis:}

The estimates of genotypic variation $(\mathrm{Vg})$, phenotypic variation $(\mathrm{Vp})$, genotypic co-efficient of variation (GCV), phenotypic co-efficient of variation (PCV), heritability $\left(\mathrm{h}^{2}\right)$, genetic advance (GA) and genetic advance in percent of mean (GAPM) for different characters have been presented in Table 2. The highest $\mathrm{Vg}$ and $\mathrm{Vp}$ were found for amylose content (805.70 and 885.28, respectively). The lowest magnitude of $\mathrm{Vg}$ and $\mathrm{Vp}$ were observed in grain breadth average ( 0.24 and 0.26 , respectively). The GCV and PCV were the highest for grain length average (90.45 and 96.49). High GCV and PCV for grain length average (90.45 and 96.49), breadth average (71.06 and 73.25), L/B ratio (58.64 and 62.10), gelatinization temperature (77.20 and 94.97) and amylose content (57.94 and 60.19) indicated that selection of these traits would be effective. The GCV and PCV was the lowest for grain yield (20.52 and 25.17). Grain yield exhibited low genotypic as well as phenotypic coefficient of variation in the present study, which may be due to presence of both positive and negative alleles in the population. High heritability was observed in breadth average (93.75), L/B ratio (91.59) and amylose content (91.01) indicated great opportunity for improvement of these characters. The GCV of grain yield was low but $h^{2}$ was moderate (77.12). High heritability estimates have been found to be effective in the selection of superior genotypes on the basis of phenotypic performance. High heritability associated with high genetic advance is highly desirable and effective in improvement program which was observed in our studied traits viz amylose content (91.0\% and 55.78), gelatinization temperature (88.7\% and 34.9) and L/B ratio (91.6\% and 49.9). The high heritability estimates along with low genetic advance indicates that non-additive type of gene action and genotype-environment interaction plays a significant role in the expression of the trait as observed in breadth average (93.75\% and 0.98$)$, protein content $(80.84 \%$ and 4.40$)$. Among the quality traits, amylose content, gelatinization temperature and L/B ratio had high heritability with high genetic advance making these characters were the most effective in the selection of aromatic rice.

Table 2. Estimation of genetic variability among different yield and quality traits of 45 aromatic rice genotypes

\begin{tabular}{l|c|c|c|c|c|c|c|c|c|c}
\hline \multicolumn{1}{c}{ Characters } & $\mathrm{Vg}$ & $\mathrm{Ve}$ & $\mathrm{Vp}$ & $\mathrm{GCV}$ & $\mathrm{ECV}$ & $\mathrm{PCV}$ & $\mathrm{h}^{2} \mathrm{~b}$ & $\begin{array}{c}\text { Genetic } \\
\text { advance } \\
(5 \%)\end{array}$ & $\mathrm{h}^{2} \mathrm{n}$ & $\mathrm{GAPM}$ \\
\hline $\begin{array}{l}\text { Grain length } \\
\text { average }\end{array}$ & 106.11 & 73.07 & 179.17 & 90.45 & 33.60 & 96.49 & 59.22 & 16.33 & 3.63 & 106.11 \\
$\begin{array}{l}\text { Grain breadth } \\
\text { average }\end{array}$ & 0.24 & 0.02 & 0.26 & 71.06 & 17.77 & 73.25 & 93.75 & 0.98 & 0.46 & 0.24 \\
$\begin{array}{l}\text { L/B ratio } \\
\text { Gelatinization }\end{array}$ & 642.13 & 58.99 & 701.12 & 58.64 & 20.43 & 62.10 & 91.59 & 49.96 & 23.21 & 642.13 \\
$\begin{array}{l}\text { temperature } \\
\text { (Score) }\end{array}$ & 323.71 & 41.04 & 364.74 & 77.20 & 55.30 & 94.97 & 88.75 & 34.92 & 9.95 & 323.71 \\
$\begin{array}{l}\text { Gel } \\
\text { consistency }\end{array}$ & 56.08 & 26.68 & 82.76 & 34.50 & 49.11 & 60.02 & 67.76 & 12.70 & 0.21 & 56.08 \\
$\begin{array}{l}\text { Amylose } \\
\text { content }\end{array}$ & 805.70 & 79.58 & 885.28 & 57.94 & 16.30 & 60.19 & 91.01 & 55.78 & 1.99 & 805.70 \\
$\begin{array}{l}\text { Protein } \\
\text { content (\%) }\end{array}$ & 5.67 & 1.36 & 7.03 & 23.16 & 10.19 & 25.31 & 80.64 & 4.40 & 0.63 & 5.67 \\
$\begin{array}{l}1000 \text { grain } \\
\text { weight (g) }\end{array}$ & 101.15 & 39.81 & 140.97 & 35.98 & 19.12 & 40.74 & 71.76 & 17.55 & 1.31 & 101.15 \\
$\begin{array}{l}\text { Grain yield } \\
\text { (kg/m }{ }^{2} \text { ) }\end{array}$ & 28.07 & 8.33 & 36.39 & 20.52 & 14.56 & 25.17 & 77.12 & 9.58 & 0.85 & 28.07 \\
\hline
\end{tabular}




\section{Multivariate analysis:}

On the basis of the relative magnitude of $\mathrm{D}^{2}$ values for all possible 270 pairs of populations, the 45 genotypes were grouped into six clusters (Table 3). The highest numbers of genotypes were found in cluster IV (21) followed by clusters I (10), V (06), II (02) and the lowest number of genotype in cluster III (01).

Table 3. Distribution of 45 aromatic rice genotypes in different clusters

\begin{tabular}{|c|c|c|}
\hline Cluster & $\begin{array}{c}\text { Number of } \\
\text { genotypes }\end{array}$ & Genotypes \\
\hline I & 10 & $\begin{array}{l}\text { Rajbhog-2, Chinikamini-2, Aglai, Sakkorkhora, Chinisakkor-1, } \\
\text { Chiniatob, Kaminisaru, Hatishail, Bashmoti and Bashmoti-1 }\end{array}$ \\
\hline II & 05 & $\begin{array}{l}\text { Radhunipagal-2, Kalijira Finer, BR-5, Badshabhog-1 and } \\
\text { Badshabhog-2 }\end{array}$ \\
\hline III & 01 & Guamori \\
\hline IV & 21 & $\begin{array}{l}\text { Premful, Badshabhog-3, Kalijira-1, Kalijira-2, awned-1, Black, } \\
\text { Uknimadhu, Tilkapur, Dubisail, BRRI dhan 37, Khaskani, } \\
\text { Dakshahi, Jirabhog finer, Badshabhog (colored), Kalgochi, } \\
\text { Chinisakkor-2, Sarukamini, Duksail, Badshabhog-4 Tapl-52, } \\
\text { Badshabhog-4 Tapl-59 and Badshabhog-4 Tapl-61 }\end{array}$ \\
\hline V & 06 & $\begin{array}{l}\text { Rajbhog-1, Chinigura, Kalizira-1, Kalizira-2, Badshabhog-4 } \\
\text { Tapl-62 and Badshabhog-4 Tapl-63 }\end{array}$ \\
\hline VI & 02 & Kalizira-3 and Radhunipagal-1 \\
\hline
\end{tabular}

Table 4. Average intra (bold) and inter cluster distances $\left(\mathrm{D}^{2}\right)$ for 45 genotypes of aromatic rice

\begin{tabular}{ccc|c|c|c|c|c}
\hline Cluster & I & II & III & IV & V & VI \\
\hline I & $\mathbf{2 . 0 3 2}$ & & & & & \\
II & 5.24 & $\mathbf{2 . 7 6 7}$ & & & & \\
III & 22.65 & 3.81 & $\mathbf{0 . 4 8 2}$ & & & \\
IV & 7.04 & 8.21 & 14.79 & $\mathbf{0 . 7 8 5}$ & \\
V & 15.10 & 15.13 & 19.23 & 13.48 & $\mathbf{1 . 3 6 4}$ & \\
VI & 9.24 & 7.12 & 15.13 & 8.98 & 12.98 & $\mathbf{1 . 0 2}$ \\
\hline
\end{tabular}

Intra and inter-cluster distance are presented in Table 4. All the inter-cluster distances were larger than the intra-cluster distance indicating presence of wider diversity among genotypes of different groups. The germplasm are traditional but they showed high variability between them which was revealed from the results of intra and inter-cluster distances.

The highest inter-cluster distance was observed between cluster I and III (22.65) followed by the distance between cluster III and V (19.23). The lowest inter-cluster distance was observed between cluster II and III (3.81) followed by the distance between cluster I and II (5.24). The maximum value of inter cluster distance indicated that the genotypes belonging to cluster III was far diverged from those of cluster I. Similarly, the higher inter-cluster values between cluster I and III (22.65), cluster III and V (19.23), cluster II and V (15.13), cluster I and V (15.10) indicated genotypes belonging to each pair of clusters were far diversed. However, genotypes within the other pair of clusters indicated that they were less diverse. The inter cluster distances in the clusters were higher than the intra cluster distances suggesting wider genetic diversity among the genotypes of different groups. Bashar et al. (2007) reported that inter-cluster distances were larger than intra-cluster distances in a multivariate analysis in rice.

The intra cluster distances ranged from 0.482 to 2.767 . Intra cluster distances in all clusters were more or less low which indicated genotypes within the same cluster 
were closely related. The highest intra cluster-distance was recorded in cluster II (2.767) containing five genotypes. The lowest intra cluster-distance was recorded in cluster III (0.482) having one genotypes. It was favored to decide that intra-cluster diversity was the highest in cluster IV i.e., more heterogeneous and intra-cluster diversity was the lowest in cluster III i.e., comparatively homogenous.

Intra cluster mean for nine characters are presented in Table 5. The data revealed that different clusters exhibited different mean values for almost all the characters except gel consistency. The highest intra cluster mean (31.24) was observed for amylose content in cluster III followed by cluster I and II. The lowest intra-cluster mean for this trait was observed in cluster VI (25.6). Protein content had the highest group mean in cluster VI (7.64) followed by cluster IV (7.26). The lowest intra-cluster mean for this trait was observed in cluster V (6.00). Grain breadth average showed the highest group mean in cluster I and cluster IV (2.16). The lowest intra-cluster mean for this trait was observed in cluster II (1.96). L/B ratio had the highest group mean in cluster I (2.32) followed by cluster II (2.24). The lowest intra-cluster mean for this trait was observed in cluster VI (1.96). Group mean for grain length average was the highest in cluster I (4.96) while it was the lowest in cluster VI (4.04). Cluster I (14.23) comprises the highest intra-cluster mean for 1000 grain weight. While the value for this character was the lowest in cluster III (11.00). Gelatinization temperature showed the highest cluster mean in cluster III (5.0). The character had the lowest value for the cluster VI (3.0). The main quantitative character for grain yield showed the highest cluster mean in cluster IV (283.80) followed by cluster I (282.68). Cluster VI (255.00) had the lowest mean value for this trait.

It is clear from the Table 6 that the highest intra cluster mean for yield and other quality characters were obtained from cluster I. Therefore more emphasis should be given on this cluster for selecting genotypes as a variety and as well as parents in crossing with other genotypes.

Table 5. Cluster mean for nine characters of 45 genotypes of aromatic rice

\begin{tabular}{l|r|r|r|r|r|r}
\hline \multirow{2}{*}{ Parameters } & \multicolumn{1}{c}{ Cluster } \\
\cline { 2 - 7 } & \multicolumn{1}{c}{ I } & \multicolumn{1}{c}{ II } & \multicolumn{1}{c}{ III } & \multicolumn{1}{c}{ IV } & \multicolumn{1}{c}{ V } & \multicolumn{1}{c}{ VI } \\
\hline Amylose content (\%) & 29.96 & 28.43 & 31.24 & 27.42 & 26.36 & 25.6 \\
Protein content (\%) & 6.85 & 6.816 & 6.50 & 7.256 & 6.00 & 7.64 \\
Grain breadth average & 2.16 & 1.96 & 2.12 & 2.16 & 2.06 & 2.065 \\
L/B ratio & 2.32 & 2.24 & 2.00 & 2.03 & 2.13 & 1.96 \\
Grain length average & 4.96 & 4.35 & 4.25 & 4.31 & 4.36 & 4.04 \\
1000 grain weight (g) & 14.226 & 11.22 & 11.00 & 13.779 & 11.35 & 13.00 \\
Grain yield (kg/m ${ }^{2}$ ) & 282.67 & 274.45 & 280.0 & 283.81 & 276.0 & 255.0 \\
Gelatinization temp (Score) & 3.6 & 3.2 & 5.0 & 3.428 & 4.0 & 3.0 \\
Gel consistency & $>60 \mathrm{~mm}$ & $>60 \mathrm{~mm}$ & $>60 \mathrm{~mm}$ & $>60 \mathrm{~mm}$ & $>60 \mathrm{~mm}$ & $>60 \mathrm{~mm}$ \\
\hline
\end{tabular}

The character contributing maximum to the divergence are given greater emphasis for deciding on the cluster for the purpose of further selection and the choice of parents for hybridization (Islam et al., 1991). Contribution of characters towards divergence obtained from canonical variate analysis is presented in Table 6. In this method, vectors or canonical roots were calculated to present the varieties in the graphical form (Rao, 1952). This is helpful in cluster analysis as it facilitates the study of group constellation and also serves as a pictorial representation of the configuration of various groups. The value of vector I and vector II revealed that both vectors had positive values for 1000 grain weight and amylose content indicating that the highest contribution of this trait towards divergence among 45 genotypes of aromatic rice. In vector I, other important character responsible for genetic divergence in the major axis of differentiation were grain breadth average, L/B ratio, grain length average, grain yield 
and gelatinization temperature having positive vector values. In vector II, protein content has positive value. Negative values for different characters in vector I and vector II had lower contribution towards divergence.

Table 6. Relative contributions of the nine principal component characters of 45 genotypes of aromatic rice

\begin{tabular}{lcc}
\hline \multicolumn{1}{c}{ Characters } & Vector I & Vector II \\
\hline Amylose content & 0.364 & 0.491 \\
Protein content $(\%)$ & -0.191 & 0.051 \\
Grain breadth average & 0.306 & -0.046 \\
L/B ratio & 0.145 & -0.390 \\
Grain length average & 0.034 & -0.581 \\
1000 grain weight $(\mathrm{g})$ & 0.588 & 0.827 \\
Grain yield $\left(\mathrm{kg} / \mathrm{m}^{2}\right)$ & 0.980 & -1.603 \\
Gelatinization temperature (Score) & 0.816 & -1.001 \\
Gel consistency & 0.00 & 0.00 \\
\hline
\end{tabular}

Considering magnitude of genetic distance and cluster means of different characters from cluster I, the genotype Basmoti, Agali and Rajbhog-2 for grain length, Rajbhog and Agali for grain width, Basmoti and Chiniatob for grain L/B ratio, Basmoti \& Rajbhog-2 for 1000 grain weight, from cluster III the genotype Guamori for amylose content and gelatinization temperature, from cluster VI the genotype Radhunipagol and Kalijira-3 for protein content, from cluster IV the genotype Kalgochi and Badshabhog-4 Tapl-59 for yield $\left(\mathrm{kg} / \mathrm{m}^{2}\right)$ might be selected as a suitable parent for future hybridization programme.

\section{REFERENCES}

Arunachalam, V. 1981. Genetic distances in plant breeding. Indian J. Genet. Plant Breed. 41: 226236.

Basher, M. K., M. A. K. Mia, M. Nasiruddin, Nur-E-Elahi, A. W. Julfiquar and M. G. Rasul. 2007. Genetic divergence based on morphophysiological characters of some maintainer and restorer lines of rice (Oryza sativa L.). In Proc. of the $7^{\text {th }}$ Biennial Conference of Plant Breeding and Genetics Society of Bangladesh. Gazipur. 72p.

BRRI. 1997. Bangladesh Rice Research Institute: Serving the Nation. Publication no. 119. Bangladesh Rice Research Institute, Gazipur, Bangladesh. 14p.

Dela Cruz, N. and G. S. Khush. 2000. Rice grain quality evaluation procedures. Pages 15-28 In: Aromatic rices. Ed. Singh RK, Singh US, Khush GS. Oxford and IBH publishing Co. Pvt. Ltd. New Delhi.

Hamid, A., N. Uddin, M. Haque. and E. Haque. 1982. Deshi dhaner jat. Publication no. 59. Bangladesh Rice Res. Inst. 117p.

Islam, M. S., M. G. Rasul, A. Bhowmic and M. A. Akbar. 1991. Genetic divergence analysis in groundnut (Arachis hypogaea L.). Bangladesh J. Plant. Breed. Genet. 8(1\&2): 35-38.

Johnson, H. W., H. F. Robinson and R. E. Comstock. 1955. Estimates of genetic and environmental variability in Soybean. Agron. J. 47: 314-318.

Mahalanobis, P. C. 1936. On the generalized distance in Statistics. Proc. Natl. Inst. Sci., India. 2: 49-55.

Rao, C. R. 1952. Advanced statistics methods in Biometric Research, Ed. John Wiley and Sons Inc. Newyork.

Singh, A. K., S. B. Singh. and S. M. Singh. 1996. Genetic divergence in scented and fine genotypes of rice (Oryza sativa L). Ann. Agric. Res. 17(2): 163-166.

Swaminathan, M. S. 1999. Rice in 2000 AD. p. 217-238 In: Rice in a variable climate. Ed: Y.P. Abrol and Sulochana Gadgil. APC Publications Pvt. Ltd., New Delhi, India. 